\title{
FUNDAMENTOS ORIENTADORES PARA AS POLÍTICAS PÚBLICAS DA EDUCAÇÃO FÍSICA NO REGIME MILITAR (1964-1985)
}

\author{
Washington Luiz de Carvalho* \\ Humberto Aparecido de Oliveira Guido**
}

\section{RESUMO}

Este texto, a partir da leitura do Diagnóstico de Educação Física/Desportos no Brasil, discute a inserção da Educação Física Esportiva (EFE) nos ordenamentos governamentais por meio de práticas de governo assentadas em análises sistêmicas. Destaca-se que o enfoque priorizado por nossos tecnocratas é o cibernético. Soma-se a essa parte, o pano de fundo que incrementou os investimentos governamentais em comodidades sociais inclusive a EFE - que viabilizassem uma melhora na qualidade de vida da população e, também, a utilização da Revista Brasileira de Educação Física como uma ação efetiva para a "disponibilização" dessa benesse social com mais qualidade.

Palavras-chave: Educação Física Esportiva. Diagnóstico. Revista Brasileira de Educação Física. Michael Foucault.

\begin{abstract}
From the reading of the Diagnosis of Physical Education/Sports in Brazil, this text argues the insertion of the Sportive Physical Education

\footnotetext{
* Mestre em Educação pela Universidade Federal de Uberlândia (UFU). Professor de Educação Física na Educação Básica da rede pública estadual na cidade de Araguari/ MG. E-mail: washingtonlcarvalho@yahoo.com.br

** Doutor em Educação na área de Filosofia da Educação pela Faculdade de Educação da Universidade Estadual de Campinas (UNICAMP). Professor do Instituto de Filosofia da Universidade Federal de Uberlândia (UFU). E-mail: guido@ufu.br
} 
in the governmental orders by means of government practices based on systemic analyses. It is emphasized that the approach prioritized by our technocrats is the cybernetic. Besides, it is also shown the background which developed the governmental investments for social comforts including the Sportive Physical Education - that may make possible an improvement on the quality of life of the population and, also, the use of the Brazilian Magazine of Physical Education, as an effective action for the accomplishment of this social benefit with more quality.

Keywords: Sportive Physical Education. Diagnosis. Brazilian Magazine of Physical Education. Michel Foucault.

\section{Introdução}

O objetivo deste texto é discutir a Educação Física Esportiva (EFE) nos ordenamentos estatais no governo militar pós-64. Pretende-se mostrar que, mais que ações conspirativas por parte do governo na condução da população, a comodidade social EFE estava associada a técnicas de governar que desde finais do século XVIII tinha na estatística, no público e na opinião desse público o alvo de suas ações. Para tanto, fazer-se-á uso do conceito de biopolítica, articulado pelo pensador francês Michel Foucault.

Assim, na primeira parte, será discutido o Diagnóstico de Educação Física Desportos no Brasil, um apanhado estatístico que procura dar sustentação às ações governamentais para atender as necessidades apontadas. O segundo ponto trata do pano de fundo que fez o governo se tornar mais sensível aos reclames da população. Por fim, discuti uma das estratégias utilizadas pelo Regime para fomentar as atividades físicas, no caso, a Revista Brasileira de Educação Física. Nas considerações finais, mostra-se que atender à população por meio de comodidades sociais é uma técnica de governo que não pode, necessariamente, ser caracterizada como ação conspirativa. 


\section{O Diagnóstico}

Levanta dados referente a níveis e variáveis, definidos para a Educação Física/Desportos no Brasil. Parte de um modelo estabelecido por análises de sistemas, observando realidade multidisciplinar. O grau de consistência desse tipo de apreciação permite alcançar uma política para efeito de ação do Governo Federal quando da utilização dos recursos da Loteria Esportiva. Fornece relação de endereços das fontes de informação (BRASIL, 1971).

Na história da Educação Física brasileira, autores clássicos como Rui Barbosa, José Veríssimo e Fernando de Azevedo eram enfáticos em relacioná-la ao desenvolvimento brasileiro. Ao discorrerem sobre sua importância, baseavam seus discursos nas ciências sociais de cunho positivista, nas ciências biológicas, e a ideia era corrigir a saúde física e moral da população pela prática dessa atividade. Sob essa perspectiva, foram se articulando "políticas públicas" para o setor, desde o final do século XIX. Mas, somente com o Diagnóstico de Educação Física/Desportos no Brasil $^{1}$, uma possibilidade concreta de governo da população, por meio dessas práticas, se mostrou viável no País. Segundo o documento,

o propósito de um diagnóstico para fins de planejamento, [...] é reunir elementos de avaliação em quantidade e qualidade suficientes que permitam, de modo objetivo e racional, definir as metas de um desenvolvimento desejado, viável de se obter em período de tempo determinado, assim como identificar os fatores sobre os quais é necessário atuar para alcançá-las. Isto implica, Lato Sensu, a realização de uma pesquisa, mas pesquisa instrumental, com fins operativos e concebida desde o início com sentido programático (BRASIL, 1971, p. 9).

\footnotetext{
${ }^{1}$ O Diagnóstico de Educação Física/Desportos no Brasil foi articulado pelo Ministério do Planejamento e Coordenação Geral por meio de um convênio entre Centro Nacional de Recursos Humanos - Instituto de Pesquisa Econômica Aplicada (CNRH-IPEA ) e a Divisão de Educação Física do Ministério da Educação e Cultura no dia 6 de maio de 1969. A partir deste ponto será designado por Diagnóstico.
} 
O Diagnóstico era uma estratégia que visava agregar o maior número de dados possíveis para serem matematizados. Esses dados poderiam ser de ordem física - em nosso caso, espaços para se praticar ou se educar por meio de atividades do corpo, capacidade da indústria em suprir as demandas por esses espaços - e humana -, quantidade de pessoas preparadas para o ensino dessas atividades, grau de conhecimento dessas pessoas, interesse dos agrupamentos humanos em participar de programas de saúde etc. A pesquisa feita deveria ser submetida a fórmulas que visassem atenuar todas as imprevisibilidades de um planejamento, ela deveria facilitar as ações de governo de um Estado que, desde o século XVIII, tendia "a aumentar o seu poder cuidando de uma maneira minuciosa e metódica, da felicidade de seus súditos de onde o nome de estado de bem-estar, Wohfahrtsstaat, pelo qual também é designado" (SENELLART, 1995, p. 2)². Sob esse aspecto, o Diagnóstico propunha a fundamentar ações do governo no planejamento de políticas públicas para a Educação Física e Esportiva. O conhecimento da realidade deveria facilitar as intenções do governo na administração das demandas da população. No caso, o Diagnóstico, viabilizaria uma ação eficaz por parte do governo na realidade esquadrinhada, pois o governo não é uma "simples instrumentalização da força de um Estado cada vez mais compacto, mas uma figura original do poder, articulando técnicas específicas de saber, de controle de coerção" (SENELLART, 1995, p. 2). O Diagnóstico, sem dúvida, era uma "técnica de saber" que facilitaria a ação governamental.

Em termos operacionais, estaríamos diante da necessidade de continuamente distinguir os aspectos técnicos, políticos e administrativos dos critérios que

\footnotetext{
2 Àqueles que poderiam objetar que o Estado brasileiro no período em questão era tudo menos um estado de bem-estar social, faz-se a seguinte ressalva: em que pese a crueldade da ditadura militar nesse momento, principalmente contra estudantes, sindicalistas e jornalistas, não se pode deixar de fazer as devidas considerações quanto às medidas governamentais de cunho social. $\mathrm{O}$ governo brasileiro, nesse momento, não coagiu apenas, ele também atuou positivamente em vários setores como a saúde, habitação, cultura, projetos de infraestrutura, etc. Que essas realizações tenham culminado em fracasso juntamente com aquilo que ficou conhecido como o "Milagre Brasileiro", é quase que um consenso. O que interessa de forma particular é o que aconteceu no âmbito da Educação Física, setor sobre o qual o governo militar agiu com determinação e cuja base de ação foi o esboço da situação dada pelo Diagnóstico.
} 
orientam os approaches, estabelecer correlação entre eles e dimensionar tentativamente as necessidades futuras (BRASIL,1971, p. 10).

Assim, o governo brasileiro, nos mesmos moldes que os de outros países, inclusive, os de origem socialistas, também estava preocupado em se munir de dados em todas as atividades da vida econômica e social para melhor administrá-la. Portanto, a recorrência a diagnósticos para planejamentos de todos os tipos não deve ser pensada como uma exclusividade do Regime Militar. Era, na verdade, uma característica de todos os governos, na qual o Brasil também se inseria e se pretendia ser o primeiro no que tange à educação física: "O Brasil é, talvez, o único país do mundo que dispõe agora de um Diagnóstico de Educação Física e Desportos, elaborado com um approach de análises de sistemas, última palavra na técnica das ciências sociais" (BRASIL, 1971, p. 8).

Mas o que significa elaborar um diagnóstico sob a última palavra na técnica das ciências sociais? Acredita-se que a ambição dos idealizadores do Diagnóstico era elaborarem o trabalho pautando-se em enfoques cuja raiz se originava em um novo paradigma: a Teoria Geral dos Sistemas. Antes de tratarmos do enfoque adotado pelos técnicos para a Educação Física, faz-se pertinente traçar um perfil desse novo paradigma.

Os técnicos-burocratas, a serviço dos políticos e na procura da melhor maneira de atender às necessidades da população, percebiam o que o "principal idealizador" dessa teoria divulgava. De acordo com Bertalanffy,

os políticos, frequentemente, reclamam a aplicação do 'enfoque sistêmico' a problemas urgentes, tais como a poluição do ar e da água, o congestionamento do trânsito, a bruma urbana, a delinquência juvenil e o crime organizado, o planejamento das cidades, etc. designando isto um 'novo conceito revolucionário'. Um primeiroministro canadense inclui a abordagem por meio de sistemas em sua plataforma política, dizendo que: 'existe uma relação entre todos os elementos e constituintes da sociedade. Os fatores essenciais dos problemas públicos, das questões e programas a adotar devem sempre ser considerados e avaliados como componentes interdependentes de um sistema total' (BERTALANFFY, 2008, p. 22-23). 
Não se pode afirmar que os políticos-militares, quando pediram aos técnicos para fazerem um diagnóstico para a Educação Física e Desportos no Brasil, tivessem em mira a concepção sistêmica, mas, quanto aos técnicos, isso é certo, pois eles entendem "que os fenômenos sociais devem ser considerados como 'sistemas' por mais difíceis e mal estabelecidos que sejam atualmente as definições das entidades sócioculturais" (BRASIL, 1971, p. 26). No entanto o que diferencia esse modelo dos modelos tradicionais?

Os modelos tradicionais são analíticos, ou seja, acredita-se que, do conhecimento das partes, pode-se, por aditividade, conhecer o todo. Nessa concepção, uma coisa leva à outra numa sequência de causalidade linear. A abordagem sistêmica, ao contrário, "consiste em preparar-se para resolver problemas que, comparados aos problemas analíticos e somatórios da ciência clássica, são de natureza mais gerais" (BERTALANFFY, 2008, p. 40). Bertalanffy, biólogo de profissão, cunhou uma expressão para abordar análises globalizantes. Ele a chamou de organísmica. O que vem a ser isso?

Tratava-se de uma teoria que decorreu da biologia e que, depois, foi rearranjada às mais variadas ciências, não para que fosse usada por esta ou aquela ciência de forma particular, mas para que facilitasse a ação de todas na resolução de problemas. Essa teoria, segundo Bertalanffy (2008), levava em consideração o organismo como totalidade ou sistema, e disso decorreu que o principal objetivo das ciências biológicas - e de todas as outras - era descobrir os princípios de organização em seus vários níveis. Desta forma, para o autor, parece que uma teoria geral dos sistemas seria um instrumento útil capaz de fornecer modelos a serem usados em diferentes campos e transferidos de uns para outros. Em que se baseia essa teoria? Na teoria dos sistemas abertos.

Sistemas abertos são aqueles semelhantes a um organismo: “o organismo não é um sistema fechado, mas aberto. Dizemos que um sistema é 'fechado' se nenhum material entra nele ou sai dele. É chamado 'aberto' se há importação e exportação de material” (BERTALANFFY, p. 62); ou seja, os sistemas abertos se relacionam com o meio. É sob a perspectiva dos sistemas abertos que o Diagnóstico é montado. No entanto, é sob o prisma de um dos possíveis enfoques sistêmicos que ele é articulado. ${ }^{3} \mathrm{O}$

\footnotetext{
${ }^{3}$ Bertalanffy (2008) enumera vários, dentre os quais o cibernético. São eles: 1) Teoria
} 
modelo apontado para o Diagnóstico da Educação Física e Desporto no Brasil é o cibernético.

A cibernética é uma teoria dos sistemas de controle baseada na comunicação (transferência de informação) entre o sistema e o meio e dentro dos sistemas, e do controle (retroação) da função dos sistemas com respeito ao ambiente. [...] Em biologia e em outras ciências fundamentais, o modelo cibernético serve para descrever a estrutura formal de mecanismos reguladores, por exemplo, por meio de diagramas de blocos e de fluxogramas. Assim, a estrutura reguladora pode ser reconhecida, mesmo quando os mecanismos reais permanecem desconhecidos ou não são descritos, e o sistema é um 'caixa preta', definida somente pela entrada e pela saída (BERTALANFFY, 2008, p. 43).

A análise do item "Modelo do Diagnóstico" exposto no Diagnóstico evidencia isso. Mas, mais do que essa análise, a Revista Brasileira de Educação Física, número 26, trouxe um artigo do coordenador e editor do Diagnóstico e da Revista - Lamartine Pereira da Costa -, que corroborou, de forma definitiva, a adoção do enfoque cibernético. Esse artigo, intitulado Caracterizações para uma politica desportiva nacional, compõe se de 22 páginas repletas de fluxogramas, em que palavras como input, output, feedback, process, control imperam do início ao fim. Lendose atenciosamente o Diagnóstico e a citação acima, pode-se entender o porquê da adoção desse enfoque. De acordo com a caracterização, o enfoque cibernético baseou-se numa estrutura reguladora formal, portanto, definida de antemão.

Dado que as informações reais da Educação Física e Desportos no Brasil não eram confiáveis, pode-se evidenciar o seguinte: os elaboradores do Diagnóstico sabiam que qualquer enfoque para se tentar administrar os problemas pertinentes à Educação Física e Desportos seria uma “caixa

clássica dos sistemas; 2) Computação e simulação; 3) Teoria dos compartimentos; 4) Teoria dos conjuntos; 5) Teoria dos gráficos; 6) Teoria das redes; 7) Cibernética; 8) Teoria da informação; 9) Teoria dos autômatos; 10) Teoria dos jogos; 11) Teoria da decisão; 12) Teoria da fila. 
preta", pois o grau de confiabilidade das informações seria mínimo. Logo, todas as medidas administrativas deveriam ser tomadas com bases nas entradas e saídas das diversas variáveis no sistema. Portanto, desde a coleta de dados, até a sua utilização para a obtenção dos objetivos, deviase estar sempre atendo às possibilidades de inserção ou retirada de dados do sistema. ${ }^{4}$ Esse enfoque, apoiado por nossos tecnocratas da Educação Física, que, de certa maneira, pretenderam abordar a realidade de forma global, ajustaram-se a uma nova arte de governar que vinha se afirmando desde o final do século XVIII e cujo objetivo era administrar a população. Assim, o enfoque cibernético, direcionado à sociedade, visava administrar fluxos da espécie humana.

Paul Veyne (1982), no texto Foucault Revoluciona a História, depois de discutir como se dava a "condução" da população no Império Romano e nas Monarquias, narra sobre a nova arte de governar da qual somos objetos:

De outras vezes, o objeto natural 'governados' não é uma fauna humana nem uma horda que, com maior ou menor boa vontade, se deixa conduzir em direção a uma terra prometida, mas uma 'população' que se tenta administrar, à maneira de um fiscal das Águas e Florestas, que regula e canaliza os fluxos naturais das águas e da flora de tal modo que tudo caminhe bem na natureza, que a flora não pereça. Ele não abandona a natureza à sua própria sorte; ocupa-se dela, mas sempre em proveito da própria natureza, ou, se preferirmos, se assemelha a um guarda de trânsito que 'canaliza' o tráfego espontâneo dos automóveis para que flua facilmente: é esse o trabalho que ele se atribui. Assim, os automóveis rodam em segurança; a isso se chama o welfare state, e nele vivemos (VEYNE, 1982, p. 155).

\footnotetext{
${ }^{4}$ Se o leitor vir uma semelhança entre esses objetivos e os malabarismos técnicos dos atuais economistas neoliberais, não é mera coincidência. Os técnicos elaboradores do Diagnóstico estavam impregnados das modernas técnicas de administração de origem neoliberal. Inclusive, deve se destacar que Bertalanffy cita os princípios teóricos de Hayek, como bons fundamentos para gestão da economia.
} 
Guardando as devidas proporções, o enfoque cibernético, aplicado à Educação Física Esportiva, visava administrar a energia física da população, orientando, canalizando essa energia, que não deveria mais ser deixada à própria sorte. Na nova arte de governar, os governantes precisavam agir sobre a natureza, no nosso caso, pretendia-se administrar o bem-estar físico da população pelo saber "Educação Física e Esportiva".

Desta forma, pode-se inferir que o objetivo era racionalizar ao máximo o orçamento disponível para aperfeiçoar os recursos humanos e físicos, com vistas a atender de forma mais eficiente à população. A palavra aperfeiçoar aparece três vezes na apresentação do Diagnóstico, que é de pouco mais que uma página.

Primeiramente, ele visava listar dados para "aperfeiçoar o homem brasileiro em todos os seus aspectos e melhorar sua qualidade de vida" (BRASIL, 1971, p. 07). Depois, em um segundo momento, aponta-se que:

[...] paralelamente ao Diagnóstico, a equipe encarregada de sua preparação tomou parte em uma série de trabalhos e medidas destinadas a aperfeiçoar o setor: a criação do atual departamento de Educação Física e Desportos; o disciplinamento dos investimentos federais nessa área; a obrigatoriedade da prática - em todos os níveis de ensino - da Educação Física e Desportiva e sua conseqüente regulamentação [...] (BRASIL, 1971, p. 8).

Mais à frente, e por último,

o diagnóstico coloca o país na posição privilegiada de poder, imediatamente, determinar uma política nacional para o setor, fundada em bases científicas e racionais, que permitirá em prazo médio, desempenhar importante papel no aperfeiçoamento dos recursos humanos disponíveis no Brasil (BRASIL, 1971, p. 8).

Temos, então, a seguinte situação: foi feito, por meio do Diagnóstico, um esquadrinhamento dos recursos físicos e humanos no que tange à Educação Física e Esportiva, cujo fim era atuar aperfeiçoando o homem brasileiro, os setores físicos, legislativos e operacionais relacionados às 
atividades e, finalmente, visava-se "aperfeiçoar" as pessoas que militavam na área no Brasil. Ora, a palavra aperfeiçoar remete a duas outras, que, em termos práticos, e nos moldes das ações tecnocráticas do período, levavam os governos a agir em função da eficiência e eficácia.

O conceito dessas duas palavras foi discutido por Manoel José Gomes Tubino e Luiz Guilherme Abtibol na Revista Brasileira de Educação Física n. $17(1973)^{5}$. Ao termo eficiência, os autores vinculavam critérios voltados para o desempenho interno e a execução, explicando que a palavra deveria ser concebida como um sistema fechado, sem relação com o meio ambiente. O termo eficácia era relacionado a critérios de desempenho externo das organizações, portanto, ele precisaria ser entendido como um "sistema aberto, com permanente e considerável envolvimento com ambiente físico e cultural" (TUBINO; ABTIBOL, 1973, p. 66). Vemos, aqui, a conexão entre os princípios que norteavam nossos técnicos e as análises sistêmicas. As expressões sistemas abertos e fechados comprovam isso. As palavras foram usadas no âmbito da eficiência e da eficácia em escolas de Educação Física, mas entende-se que os termos decorriam de um padrão de ação dado pelos objetivos governamentais, tendo em vista que, segundo os autores, governar era levar uma empresa até seu objetivo (eficácia), tratando de fazer o melhor uso possível de todos os recursos que estavam a sua disposição (eficiência).

O Diagnóstico visava possibilitar, por meio da elaboração de dados estatísticos, a maior eficiência na administração dos recursos disponíveis para a maior eficácia no atendimento das necessidades detectadas pelos relatórios. Dessa forma, podem-se fazer duas perguntas: 1) sob que perspectiva os dados do Diagnóstico deveriam ser arranjados para que atendessem às necessidades governamentais de eficiência e eficácia? e 2) elaborado o Diagnóstico e os objetivos a serem alcançados, qual o melhor sistema para inseri-lo?

Quanto à primeira questão, o Diagnóstico não se limitava apenas a detectar os problemas pertinentes à realidade estudada, ele deveria também:

\footnotetext{
${ }^{5}$ A partir de agora designada por REVISTA.
} 
Conjugar-se com a identificação dos objetivos desde o início da ação governamental [...] prevendo as melhores condições possíveis para a efetividade da atuação administrativa. Em termos práticos, esse enfoque pode ser delineado partindo-se da análise comparada conjuntural da Educação Física/Desportos em outros países, procurando-se determinar tendências globais (BRASIL, 1971, p. 18).

As bases comparativas, sobre as quais os planejamentos governamentais assentavam os seus objetivos - determinados de acordo com padrões internacionais - eram advindas dos órgãos oficiais da UNESCO, que advogavam, como primeiro ponto, ser a Educação Física/Desportos educacionais, o fundamento de todo projeto na área. Segundo, essas atividades visavam à melhoria da saúde da população; terceiro, cabia às organizações comunitárias - de todo tipo - a efetividade das ações do governo.

À segunda questão, os organizadores do Diagnóstico apresentavam como solução a inserção dos dados da realidade estudada e os objetivos a serem alcançados em um sistema no qual possíveis causas de desvios nas metas traçadas fossem detectadas com antecedência e realinhados os fatores determinantes desses desvios. Assim, elaboraram um fluxograma cuja

configuração representa, de forma genérica, a problemática de qualquer empreendimento moderno e mostra, sobretudo, a interdependência do planejamento com a antecipação do futuro, característica que é interpretada por uma das definições correntes: 'planejamento é a construção de modelos de antecipação causativas. (BRASIL, 1971, p. 18).

A que se queria chegar com esses modelos de antecipação causativas? O objetivo era, por meio do enfoque cibernético, atuar equacionando os resultados pouco produtivos dos investimentos e das ações efetuadas pelo governo na administração da comodidade Educação Física e Esportiva à população. Mas, para a adoção desse enfoque, fazia-se necessário, antes de tudo, uma opção de modelo estrutural a ser seguido pelo governo, e este é dado na REVISTA.

Em matéria intitulada Educação Física no Brasil de 1970 para 1980, n. 12, ano 4, os autores, depois de compararem três modelos/ 
sistemas administrativos para o setor, asseguravam ser ideal, para o Brasil, o chamado sistema misto. Todos os três sistemas se apresentavam em um esquema piramidal cuja base é escolar, o meio da pirâmide é caracterizado como social e o ápice é composto pela elite. O primeiro foi designado de "Dirigismo Absoluto", e as três fases da pirâmide não se comunicavam. Segundo os articuladores, esse sistema foi característico dos regimes totalitários. O segundo, designado de "Liberalismo Absoluto" foi comum nos países já desenvolvidos, como os Estados Unidos, e a base e o meio da pirâmide se comunicavam. No terceiro, segundo os autores, o melhor para o Brasil, chamado de "Sistema Misto", as três fases se comunicavam, e caberia ao governo orientar as atividades da base escolar com a participação dos setores privados e da comunidade, desde que submetidos à ordenação governamental.

Justificavam a opção, tendo como base o Diagnóstico, para o planejamento das ações governamentais, nos seguintes termos:

\section{Opção Brasileira}

No ordenamento das prioridades de ação, o Governo brasileiro, após 1694, fez do homem a sua meta prioritária. Partindo deste enfoque, foi elaborado em 1968/69 o "Diagnóstico de Educação Física/Desportos no Brasil". Conhecida a situação real, e as possibilidades de ação oferecidas pela tecnologia, qual a opção?

As próprias determinantes de cada uma das correntes existentes levaram à conclusão de que, por sua formação étnica, status econômico e orientação político-social, a melhor opção para o Brasil era a da "Orientação Mista".

\footnotetext{
${ }^{6}$ Entende-se que a opção pelo sistema misto pode ser explicitada pela própria postura governamental brasileira a partir da Proclamação da República. Embora o País tenha optado pelo liberalismo, nunca deixou de agir por meio do Estado nos mais variados setores. Desta forma, a estrutura governamental foi sempre, no limite, semelhante ao "monstro" do Doutor Frankenstein. Isso porque, adotando as ideias liberais, nunca deixou de agir arbitrariamente por meio do Estado, fosse impondo políticas públicas ou solapando princípios democráticos.
} 


\section{Planejamento Geral}

Estabelecida a linha geral de conduta, foi estruturado o sistema político administrativo, a ser instalado por etapas, observando-se os feedbacks que agiriam sobre as variáveis dos sistemas.

Esta forma de ação elimina qualquer ingerência estranha ao setor na distribuição orçamentária e assegura o controle efetivo da execução dos projetos: ao Estado, e somente a este, cabe programar o seu desenvolvimento.

Excepcionalmente, age ainda o DED através de grupos de trabalho especiais, de duração limitada e com atribuições específicas (REVISTA, 1972, n. 12, p. 85).

Analisando-se os fluxogramas, observa-se que o governo, por meio de uma política nacional de Educação Física e Desportos, tinha como objetivos atuar diretamente sobre a população e também o domínio sobre a estrutura de transformação, composta pelos equipamentos primários, equipamentos básicos e organização desportiva comunitária, e, sob esse último, recaía a ideia de que o desenvolvimento seria mais viável com a participação da comunidade. Todo processo subsequente deveria estar realimentando o setor de planejamento recursos humanos com dados para nova ação governamental.

Observa-se, nessa colagem do Diagnóstico aos pressupostos da UNESCO e da opção pelo sistema misto, o direcionamento dos programas de governo para o controle da população. Tendo a Educação Física e Esportiva como uma comodidade social que poderia gerar lucros ao governo, tanto no que se relacionasse aos aspectos da população em sua totalidade, bem como nos aspectos individuais, o governo passaria a investir nessa prática. De forma específica, no direcionamento da ação governamental à população, Foucault a denominou de biopolítica. Uma tecnologia

que se instala, se dirige à multiplicidade dos homens, não na medida em que eles se resumem a corpos, mas na medida em que ela forma, ao contrário, uma massa global, afetada por processos de conjunto que são próprios da vida, que são processos como o nascimento, a morte, a produção, a doença, etc... (FOUCAULT, 2005, p. 289). 
Mas por que tanto zelo com a população? Por que tanta preocupação em conhecer suas necessidades e seus desejos? Haveria algum "fantasma" que atemorizava o governo para que criasse políticas para administração dessa população? A resposta é positiva, havia sim. Tratava-se do medo do comunismo.

\section{Pano de Fundo}

Estamos vivendo um processo de guerra permanente, que nos é movido pelo mundo comunista, que tem como meta o seu expansionismo, impondo sua ideologia aos países democráticos. É imperativo, portanto, que nos preparemos para enfrentá-los em todas as áreas $e$, em particular, na expressão psicossocial do Poder Nacional, a mais sensivel e vulnerável às investidas da subversão dentro do processo guerra revolucionária, que procura a conquista dos individuos e, por via de conseqüência, a do Estado visado. Escola Superior de Guerra. Departamento de Estudos. TG4-76. $4^{\circ}$ Trabalho de Grupo. Análise da conjuntura/interna (Escola Superior de Guerra apud ROSEMBERG, 1977, p. 141-161).

Depois da Segunda grande Guerra Mundial, o mundo esteve em tensão permanente devido à iminência de um conflito mundial entre as duas maiores potências do mundo. No lado ocidental, os Estados Unidos da América lideravam um bloco de países que defendiam ideias liberais e, pelo lado oriental, a União das Repúblicas Socialistas Soviéticas encabeçava um grupo de países que se pautavam pelos ideais comunistas. A busca por estender sua influência ao maior número de países do planeta predispunha-os a um jogo de ameaças constantes, em que a população se via assombrada sob a possibilidade da deflagração de uma guerra de consequências inenarráveis. Em decorrência dessa situação, todos os países ligados, direta ou indiretamente, às duas potências hegemônicas do período passaram a desenvolver estratégias que os mantivessem incólumes às ideias e ao desenvolvimento de ações práticas em seu território que não se coadunassem às suas opções ideológicas. O Brasil não estava fora desse contexto e, desde 1949, desenvolvia ações calcadas na 
chamada Doutrina de Segurança Nacional (DSN). Segundo Silva (1967), A DSN tinha como diretrizes governamentais quatro estratégias: política econômica, psicossocial e militar. E para que uma tivesse o melhor êxito possível, era necessário que a Estratégia Geral (DSN) as concebesse como interdependentes:

a essa estratégia se subordinam, pois, tanto a Estratégia Militar como a Estratégia Econômica, a Estratégia Política e uma Estratégia Psicossocial, as quais se diferenciam uma das outras pelos campos particulares de aplicação e pelos instrumentos de ação que lhes são próprios, embora nunca deixem de atuar solidariamente, seja no tempo, seja no espaço (SILVA, 1967, p. 25).

Silva (1967), como principal articulador da DSN, sabia perfeitamente que, num mundo em guerra total e permanente, não bastava o investimento em armas e coisas afins. Era forçoso que, juntamente com essas medidas, fossem tomadas outras cujo fim fosse assegurar o bem estar da população. Para se conseguir o mínimo de segurança era imperioso um mínimo de bem-estar da população, pois o completo descuido desse item por parte do governo poderia levá-lo ao insucesso. Portanto, segurança e bem-estar da população se relacionavam numa equação na qual, a partir de determinado ponto, o excessivo investimento em uma implicaria o decréscimo da outra. Mas Silva ainda alertou para o perigo de não se cuidar da população em uma situação de guerra total:

A segurança estrutura-se, pois não pode deixar de estruturar-se, sobre uma base irredutível de bem estar econômico e social, nível abaixo do qual se ofenderá a própria capacidade de luta e de resistência da nação, incapacitando-a, afinal, para um esforço continuado e violento que dela a guerra exigirá. Esta é bem um domínio em que as forças morais cabe papel saliente, e não há moral de um povo que se possa manter indene além de certos limites de exaustão e de desânimo (SILVA, 1967, p. 14).

Ora, o que a DSN vislumbrava como problema de governo era a população. Esse acontecimento não era nenhuma novidade, e Michel 
Foucault o contextualizava a partir de fins do século XVIII e início do século XIX. Com relação à população, o autor afirmava, "É um novo corpo: um corpo múltiplo, corpo com inúmeras cabeças, se não infinito pelo menos necessariamente numerável" (FOUCAULT, 2005, p. 292). Os nossos ideólogos sabiam que a população era problema do governo, e, como mostrou a citação de Silva (1967), a segurança do Estado decorreria do bom ânimo do povo de uma nação, e este só poderia ser consequência de estratégias políticas que cuidassem de todos. Em termos foucaultianos, a DSN era uma ação biopolítica, pois lidava "com a população, e a população como problema político, como problema a um só tempo científico e político, como problema biológico e como problema de poder" (FOUCAULT, 2005, p. 292-293).

Tendo em vista o contexto histórico decorrente da Segunda grande Guerra, pode-se compreender a preocupação dos governos ocidentais em conhecer e agir preventivamente em áreas de risco mais vulneráveis à disseminação de ideias comunistas para melhor administrá-las, por meio das chamadas comodidades sociais (habitação, saúde, educação, etc.). A Educação Física/Desportiva estava no planejamento desses órgãos, pois foi detectado em pesquisas internacionais que:

1. A recreação passiva e ativa - incluindo a Educação Física/ Desportiva - é classificada juntamente com a escolarização, habitação, atendimento médico e facilidade de abastecimento na categoria de comodidades sociais para efeito de planejamento de recursos humanos.

2. [...] Entretanto, são indubitáveis as verificações de benefícios advindos do investimento em comodidades para o desenvolvimento de um país ou região.

3. O inter-relacionamento das comodidades sociais tem sido comprovada por meio do fato de que os programas coordenados e integrados de educação, saúde, habitação e recreação apresentam efetividade sobre maneira relevante em relação a um desses fatores abordado isoladamente (BRASIL, 1971, p. 25). 
Logo, a Educação Física, como estratégia psicossocial, não poderia estar fora das ações biopolíticas do governo. O Regime Militar, implantado a partir de 1964, visando à governabilidade do País, agia sob três pontos básicos: 1) tentava possibilitar o acesso da população às comodidades sociais; 2) agia com repressão física e luta armada contra dissidentes, principalmente, estudantes, professores e alguns setores como sindicatos e jornalistas e 3) também agia com propaganda de cunho nacionalista e de depreciação dos comunistas. $\mathrm{O}$ ataque a estes últimos podia ser sutil como o de um artigo na Revista Brasileira de Educação Física de número 17.

Em um texto, aparentemente despretensioso, com o título Observações sobre detalhes técnicos e problemas do voleibol e dos demais desportos coletivos, o autor, Adolfo Guilherme, deixou explícito o pano de fundo que determinava as ações e os planejamentos dos órgãos oficias ou privados no mundo ocidental. À primeira vista, ninguém poderia supor que, em um texto cujo título fala em "detalhes técnicos", "problemas do voleibol", houvesse insinuações sobre comunismo. Somente tendo em vista o fundo histórico sobre o qual a história era construída, pode-se chegar a essa conclusão.

O autor, ao falar dos problemas técnicos, não se reportou a problemas específicos das técnicas instrumentais do jogo em si, ele fez alusão aos problemas dos técnicos com os jogadores e dos jogadores com os seus colegas. Ao falar dos líderes e de suas ações na equipe, não perdeu tempo com as qualidades negativas e enumerou 21 destas dentre as quais: conspirar contra a direção técnica; estar solidário com o companheiro faltoso; estimular a indisciplina e a desordem; procurar dividir a turma em "grupinhos", a fim de desfazer a unidade da equipe. No que tange às qualidades positivas, listou apenas quatro, das quais se destacavam: cooperar com a direção técnica; ter capacidade de orientar a turma para o bom caminho ${ }^{7}$. Mas, nas notas, percebe-se o fundo histórico sob o qual escrevia suas "observações":

\footnotetext{
${ }^{7}$ Frente a uma discrepância tão grande entre qualidades negativas e positivas na Educação Física e Esportiva, pode-se indagar se essas práticas seriam realmente um bom instrumento para a educação.
} 
A ação do falso líder dentro de uma equipe é tão prejudicial e perigosa quanto a do subversivo dentro de uma Nação. Esta comparação se justifica porque enquanto o subversivo repudia sua pátria, perde o amor à sua família e á sua própria vida, o falso líder conspira contra o êxito de sua Agremiação ou Entidade Esportiva [...] sendo os meios esportivos próprios para aglutinar pessoas de ambos os sexos e de todas as idades em uma atividade sadia, pura, saudável, alertamos aos treinadores e aos dirigentes esportivos para ficarem permanentemente atentos, a fim de coibir e interceptar a ação negativa e prejudicial destes elementos, entre pessoas inocentes e desprevenidas. Enfim, tanto o subversivo como o falso líder são enfermos - maníacos perniciosos e nocivos às instituições e à sociedade (GUILHERME, 1973, p. 61).

Assim, numa revista que tinha divulgação nacional e que possuía "autoridade" frente aos seus leitores, isso não representava pouca coisa. Pode-se considerar estarrecedora a comparação que o autor fez: maníacos perniciosos e nocivos. A raiva com que Guilherme se referia aos falsos líderes não seria compreensível sem esse fundo histórico enredado na chamada Guerra Fria. Palavras como Pátria, família, vida, reforçavam as dimensões sobre o fundo em que a história era escrita - a manutenção dos valores ocidentais de cunho cristão e liberal em oposição aos comunistas de origem socialista.

Esse artigo foi citado, não para mencionar que houvesse uma mentalidade conspirativa por parte dos articuladores da REVISTA e do autor do texto. Pretendeu-se apenas contextualizar o fundo sob qual se desenrolava a história e que obrigava os governos a agir preventivamente no atendimento dos desejos da população, disponibilizando comodidades sociais que mitigassem suas necessidades básicas. A Revista Brasileira de Educação Física e Desportos, como um veículo divulgador de saberes técnicos e pedagógicos, foi ao encontro das necessidades destacadas para um melhor atendimento dessa benesse social à população. Por quê e como?

\section{A Revista}

A Campanha Nacional de Esclarecimento Desportivo pretende ir ao encontro das melhores aspirações do Professor de Educação Física, mas também deseja receber a sua colaboração. Entre as suas peças 
encontra-se essa Revista, reformulada agora para desempenhar um efetivo papel nesta fase (A.E.J., 1972, p. 05).

O capítulo número 13 do Diagnóstico intitulado Unidade Funcional do Sistema, detectou que, no Brasil, o tema Educação Física/Desportos foi um dos mais veiculados na imprensa, mas, em contrapartida, foi um dos que mais careceu de uma abordagem técnica. Na página 332, lê-se o seguinte:

Pode-se, portanto, concluir que a Educação Física/Desportos representa no País um dos mais importantes fluxos de informação quanto a intensidade, como também deve ser essencialmente de caráter noticioso dado aos tipos de veículos mais utilizados (jornais, rádio, e televisão). A tiragem insignificante dos livros e folhetos, em termos relativos, e a existência de apenas uma revista técnica efetivamente periódica ("Boletim Informativo", tiragem de 5.000 exemplares, editado pela Divisão de Educação Física do MEC e recentemente transformada em "Revista Brasileira de Educação Física e Desportiva") confirmam essa interpretação (BRASIL, 1971, p. 332).

Da citação acima, pode-se compreender o porquê da REVISTA nas estratégias do governo. Ela se apresentava como um veículo de divulgação técnica dos conhecimentos da área e era concebida como um instrumento de saber que facilitaria as pretensões do governo em atender à população na comodidade Educação Física e Desportos. Tendo em vista que o Diagnóstico detectou uma carência muito grande de informações técnicas, a REVISTA e outros meios poderiam solucionar o problema. A esse respeito, valem as seguintes palavras:

Os impedimentos para a aceleração do processo situam-se, na atualidade, no referente à participação deficiente das informações de natureza técnica e administrativa. Em termos de política nacional, essas carências são traduzidas, respectivamente, em programação visando a qualidade - em lugar da normalmente preconizada objetivando quantidade - e a reforma concomitante da estrutura e funções da intervenção governamental (BRASIL, 1971, p. 333). 
A REVISTA estava dentro dos objetivos governamentais que deveriam contemplar em primeiro lugar a qualidade das informações transmitidas. Sobre as novas pretensões do governo para a divulgação da REVISTA, foram decisivas as palavras do Coronel Eric Tinoco Marques no editorial da REVISTA n.13, cujo título foi: Faça sua revista circular. Explicava ele:

Você deve estar sentindo a modificação gradual da sua Revista. Pelo menos, assim esperamos que aconteça e, neste sentido temos envidado o melhor de nossos esforços. Meridiano se torna que a implantação de uma publicação periódica seja tão atualizada quanto possível, cobrindo a maior área de assuntos que o seu espaço possibilite; destarte, a elevação do seu padrão técnico deve ser acompanhada de perto pela diversificação do conteúdo, sem esquecer a apresentação (MARQUES, 1973, p. 04).

Assim, tem-se que a REVISTA era "tão atualizada quanto possível", de alto "padrão técnico", diversificada em seu conteúdo e de boa apresentação. Todos esses pontos tinham como objetivo seduzir os profissionais da área para atuarem juntos e com qualidade na expansão da comodidade social Educação Física e Esportiva para a população brasileira.

O Coronel Eric Tinoco Marques, no editorial da REVISTA 14, intitulado Um novo mercado de trabalho, corrobora de forma definitiva as palavras acima e, justifica, apontando que

um dos pontos mais delicados do sistema Educação Física/Desportos, segundo a constatação do Diagnóstico de Educação Física/Desportos no Brasil, dizia respeito à falta de "circulação e transmissão de conhecimentos técnicos". Dependíamos, neste setor, de centros estrangeiros, e a bibliografia para consulta era composta quase que exclusivamente de autores de outros países. Evidentemente isso prejudicava de modo sensível a formação de nossos técnicos e especialistas. Tínhamos bons valores militando entre nós, e estes, por certo, teriam condições de produzir o material tão reclamado; faltavam-lhes, porém, o estímulo, o tempo e a oportunidade de terem seus trabalhos publicados. Mister se fazia agir de imediato 
para possibilitar o encontro de uma solução. E assim partimos para o tratamento do setor, dando início a uma programação editorial maciça e bastante diversificada, no corpo da Campanha Nacional de Esclarecimento Desportivo - e aqui o ponto central -, indo mais além do que os objetivos inerentes à Campanha. Através desta, tivemos a oportunidade de poder começar um trabalho de estímulo ao escritor desportivo. Ora, se a falha central residia na falta de oportunidade, nas dificuldades de editoração, nada mais fácil do que, resolvendo tais problemas, chegar à tão desejada produção; [...] O fato é que em 1972 logramos colocar em circulação a primeira série de nossas publicações, e inauguramos 1973 com a nova Revista, já dentro de um esquema totalmente reformulado. Agora transferimos os problemas para você, caro leitor: esta Revista é sua, até porque, se não fosse você, não teria razão a sua existência, e muito menos o nosso trabalho. Participe, usando-a para veicular a sua opinião, para difundir seu conhecimento, para permitir que outros se valham de sua experiência. Este é um novo mercado de trabalho à disposição do professor de Educação Física. Não fique por fora (MARQUES,1973, p. 3-4).

Dos editoriais percebe-se o como da REVISTA. Ela estava inserida numa Campanha Nacional de Esclarecimento Desportivo, que visava atender com mais qualidade à população, e, de forma especial, aos jovens e às crianças. Assim, ela deveria facilitar a atuação dos professores de Educação Física na formação do caráter dos homens do País e também despertar uma consciência desportiva nacional. Concluindo, o porquê da REVISTA deve-se a deficiências técnicas em informativos para a área de Educação Física e Esportiva, e o como do periódico tinha em vista facilitar a produção de uma consciência esportiva nacional, principalmente por meio da atuação dos professores de Educação Física.

\section{Considerações finais}

A partir das considerações feitas anteriormente, podemos concluir que o governo brasileiro "investiu" muito no conhecimento da realidade física e humana que sustentava a Educação Física no País. O Diagnóstico é significativo dessa intenção. Observou-se, também, que se procurou aplicar 
à realidade percebida, o que os tecnocratas a serviço do Regime supunham ser o melhor em termos científicos - análises sistêmicas - para gerenciar a comodidade social EFE à população. Foi articulada uma Campanha Nacional de Esclarecimento Desportivo e dentre suas ações para o fomento das práticas físicas foi aprimorada a Revista Brasileira de Educação Física.

Tal empenho, em conhecer e facilitar o acesso da população a esse benefício social, foi comum tanto aos regimes reacionários da direita quanto aos totalitários da esquerda. Portanto, no Brasil, entre os anos de 1964-1985, se justifica pensar, à esquerda, que o governo, por meio da Campanha Nacional de Esclarecimento Desportivo, agia conspirativamente na condução da população. Mas também é compreensível entender que à direita se concebesse essas ações como representativas de um governo muito bem intencionado. Mas também, se pode pensar essas ações sob um novo prisma. Como?

Estas duas perspectivas remetem a análises simplistas de tipo maniqueístas, que mais estigmatizam do que esclarecem sobre o público como fundamento de uma nova maneira de governar que vinha se consolidando desde o século XVIII. Nessa nova forma de governo se está “longe da idéia 'virtuosa' de uma comunicação do monarca com os seus súditos no conhecimento comum das leis humanas, naturais e divinas. Longe também da ideia 'cínica' de um príncipe que mente aos seus súditos para melhor assentar e conservar seu poder" (FOUCAULT, 2008a, p. 367368); pois, a população, o público, aparece, a partir dessa data, "como sujeito-objeto de um saber: sujeito de um saber que é 'opinião’ e de objeto de um saber que é de tipo totalmente diferente, porque tem a opinião como objeto e porque esse saber de Estado se propõe modificar a opinião ou utilizá-la, instrumentalizá-la" (FOUCAULT, 2008a, p. 367-368).

Essas novas tecnologias de governo que se estenderam tanto à direita quanto à esquerda, objetivavam constituir sobre a população um saber para agir sobre ela, pois a "governamentalidade é a maneira como se conduz a conduta dos homens" (FOUCAULT, 2008b, p. 258). Quando se passa a pensar por meio dessa perspectiva, descortina-se o problema da relação governo/governados para além dos simplismos manipuladores/manipulados, pois a população não aparece como destituída de uma opinião, que deve, no mínimo, ser considerada na articulação das políticas públicas. 
Tomemos como exemplo o esforço do governo brasileiro em facilitar o acesso da população à comodidade social Educação Física Esportiva. O que foi feito? Foi realizada uma pesquisa, na qual, dentre outras coisas, se detectou que o interesse por Educação Física, Esportes, Lazer era muito grande. Procurou-se administrar as carências e os investimentos para o setor por meio do enfoque cibernético, fundado sob a perspectiva sistêmica. Concomitantemente, se articulou uma Campanha Nacional de Esclarecimento Desportiva e uma Revista técnica para tratar dos assuntos.

Com estas observações, podemos concluir dizendo que, se análises maniqueístas, ao colocar de um lado manipuladores e de outro manipulados, não podem ser descartadas, também não podemos deixar de tratar dessa relação por uma perspectiva que reconhece nas ações governamentais, mais do que simples artimanhas ideológicas, pois, a arte de governar trata, antes de tudo, da conduta das pessoas. Mas essa arte esta limitada ao momento histórico. Assim, não seria concebível, falar em estado de bem-estar social antes do mundo industrial, pois não havia um mundo de riquezas que possibilitasse tal condição. Assim, o Regime Militar, tal qual os países capitalistas e socialistas, investiu em benefícios para atender à população. Se agiram afinados aos ordenamentos neoliberais é uma questão não menos importante e que merece ser desdobrada, mas sem cair em análises conspirativas.

\section{Referências}

A.E.J. É tempo de somar. Revista Brasileira de Educação Física. Brasília, n. 11, p. 3-7, 1972.

BERTAlAnfFy, L. V. Teoria Geral dos Sistemas. Petrópolis: Vozes, 2008.

BRASIL. Diagnóstico de Educação Física/Desportos do Brasil. Ministério do Planejamento, Brasília, 1971.

FOUCAULT, M. Em defesa da sociedade. Tradução de Maria Ermantina Galvão. São Paulo: Martins Fontes, 2005. 
. Segurança, Território, População. Tradução de Eduardo Brandão. São Paulo: Martins Fontes, 2008a.

. Nascimento da biopolitica. Tradução de Eduardo Brandão. São Paulo: Martins Fontes, 2008b.

GUILHERME, A. Observações sobre detalhes técnicos e problemas do voleibol e dos demais desportos coletivos. Revista Brasileira de Educação Física, Brasília, n. 17, p. 54-63, set./out. 1973.

MARQUES, E. T. Faça sua revista circular. Revista Brasileira de Educação Física. Brasília, n. 13, p. 3-5, jan./fev. 1973.

. Um novo mercado de trabalho. Revista Brasileira de Educação Física. Brasília, n. 14, p. 3-4, mar./abr. 1973.

MOLLET, R. Educação Física e Desportos no Brasil de 1970 para 1980. Revista Brasileira de Educação Física, Brasília, n. 12, p. 81-87. 1972.

COSTA, L. P. da. Caracterizações para uma política desportiva nacional. Revista Brasileira de Educação Física e Desportos. Brasília, n. 26, p. 2042, abr.jun. 1975.

ROSEMBERG, F. ALBA, O Projeto Casulo e a Doutrina de Segurança Nacional. In: FREITAS, M. C. (Org.) História Social da Influência no Brasil. São Paulo: Cortez, 1977.

SENELLART, M. A crítica da razão governamental e Michel Foucault. Tempo Social, Revista de Sociologia, São Paulo, v. 7.p. 1-2; p. 1-14, Out. 1995.

SILVA, G. do C. e S. Geopolítica do Brasil. Rio de Janeiro: Livraria José Olympio Editora, 1967.

TUBINO, M. J. G.; ABTIBOL, L. G. Os conceitos de eficiência e eficácia e uma abordagem preliminar analítica em escolas de educação física. Revista Brasileira de Educação Física, Brasília, n. 17, p. 64-73, set./out. 1973.

VEYNE, P. M. Como se escreve a história, Foucault revoluciona a história. Tradução de Alda Baltar e Maria Auxiliadora Kneipp. Brasília: Editora da Universidade de Brasília, 1982. 